\title{
Arcana of the Magus of Lunar Magnetism in the Life of a Native
}

\author{
Y. V. Subba Rao \\ Department of Science and Instrumentation, University Science and Instrumentation Centre, Sri Venkateswara University, Tirupati, India \\ Email address: \\ yvsubbarao2004@yahoo.com
}

\section{To cite this article:}

Y. V. Subba Rao. Arcana of the Magus of Lunar Magnetism in the Life of a Native. International Journal of Biomedical Engineering and Clinical Science. Vol. 3, No. 5, 2017, pp. 73-77. doi: 10.11648/j.ijbecs.20170305.14

Received: March 31, 2017; Accepted: May 5, 2017; Published: October 31, 2017

\begin{abstract}
Lunar Magnetism which seem to greatly influence the various stages of a native such as female menstrual cycle, ovulation, fertilisation, formation of zygote, development into embryo, foetus, childbirth and all stages of life of the native to the point of termination of mundane existence corroborates with Vedic Astrology and Seymour's findings of the resemblance between Gauquelin's four-pronged pattern for Venus, Mars, Jupiter, Saturn, and the Moon and the pattern for the monthly average of the lunar daily magnetic variationis discussed in this paper.
\end{abstract}

Keywords: Planetary Heredity, Magnetism, Menstruation, Zygote, Zodiac

\section{Introduction}

The Moon is a minor or a secondary planet. It is a satellite or companion of the primary planet, our Mother Earth, and revolves around it. It is included for purposes of Vedic Astrology but Moons of no other planet are included. Omnipresent throughout the universe, magnetism is known to affect the biological cycles of numerous creatures here on Earth, including humans.

Seymour states that "Gauquelin's planetary heredity links [1] involving the four-pronged pattern, involving two large peaks and two small peaks, that emerges for Venus, Mars, Jupiter, Saturn, and the Moon, is very similar to the shape of the average lunar daily magnetic variation for one month" [2] (Figure 1). This suggests that the combined complex interactions of planetary forces might be acting upon the Moon because of which Moon plays such a great role in the life of a native from zygote stage to the of point of termination of mundane existence.

There are a several stages involved in the child's birth. It involves female menstruation, ovulation, fertilisation and formation of zygote, embryo and foetus, and finally child's birth. Each stage is described with the role of lunar magnetism involved in the background of principles of Vedic Astrology.

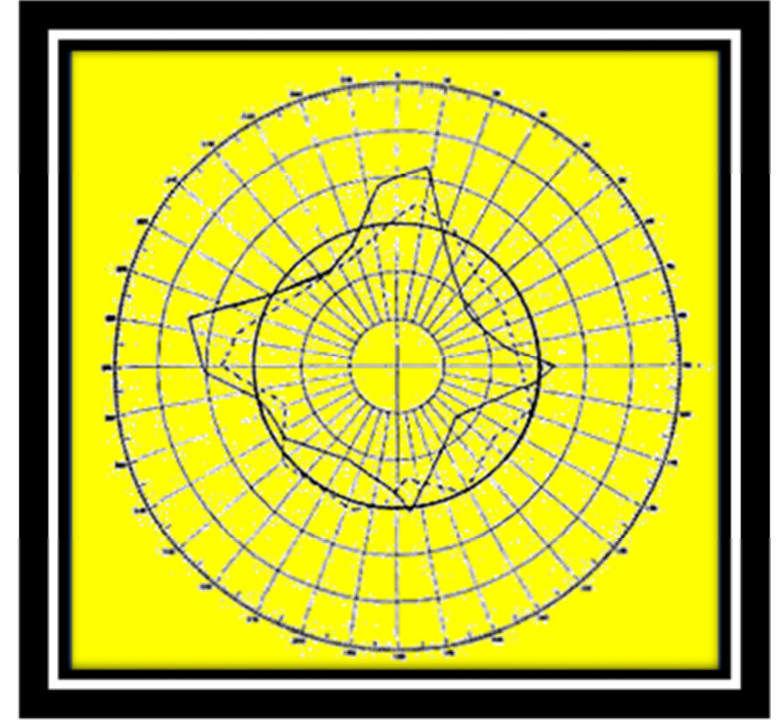

Figure 1. (Courtesy: Michel Gauquelin, Planetary Heredity, San Diego: ACS Publications, 1988. «Text) Four-pronged Pattern of Gauquelin's Planetary Heredity.

\section{Abstraction and Representation of a Phenomenon}

The word "menstruation" is etymologically related to 
"moon". The terms "menstruation" and "menses" are derived from the Latin mensis (month), which in turn relates to the Greek mene (moon) and to the roots of the English words month and moon.

The first step in abstraction requires a representation of a phenomenon through a number. If two phenomena have the same number assigned to them, then they are said to be related. In Aitreya Aranyaka, the parallels between the planetary motions and man are thus drawn.

The alignment of the two planets Moon and Mars and the magnetic fluctuations of these two given planets might cause female neural network to respond to these signals. Mars and Moon have permanently magnetized patches of rock on their surfaces. Moon and Mars are therefore two permanent magnets. These two planets in opposition with their like poles oriented towards each other results in repulsion and probably causes female menstruation (Figure 2); and, when they are in conjunction, a fortnight after menstruation, with their unlike poles facing each other causes ovulation due to attraction (Figure 3). Female menstruation and ovulation respond to certain positions of the transit Moon in the sky per se in relation to Natal Moon per se and Natal Mars per se [3]. Thus, the position of the Moon, both transit and natal, is important for female menstruation and ovulation.

The time periods of revolution of Moon and Mars have a corresponding coincidence with menstrual cycle and ovulation. The average duration of pregnancy (from ovulation to birth) in the human is rather precisely nine synodic months (1 Synodic Month = 29.53days) of the Moon. A fundamental harmony thus exists between the universe and the individual.

\section{Variable Menstrual Periods: Natural Cure}

Women with variable onset of menstrual periods, artificial illumination of the bedroom through the $14^{\text {th }}$ to 17 th nights following the onset of menstruation resulted in the regularization of the period. (Encyclopaedia Britannica (1994; Macropaedia article on Animal Behaviour, p. 761)

VarāhaMihira, Astronomer and Astrologer par excellence, says that Moon and Mars in a woman's horoscope are the cause for bringing about menstrual cycle in women [4]. Because of Moon's transit in Anupachaya Signs mean Signs other than 3, 610 and 11 from her natal Moon and in aspect of Natal Mars in a woman's chart, the female obtains her menses. This can be easily verified to be true. Kalyāna Varma explains that Moon is water and Mars is fire. Water produces blood and fire produces bile. When blood is enraged by bile, the woman gets her menstruation [5]. NASA reported availability of abundant water on Moon, and Mars has volcanic activity.

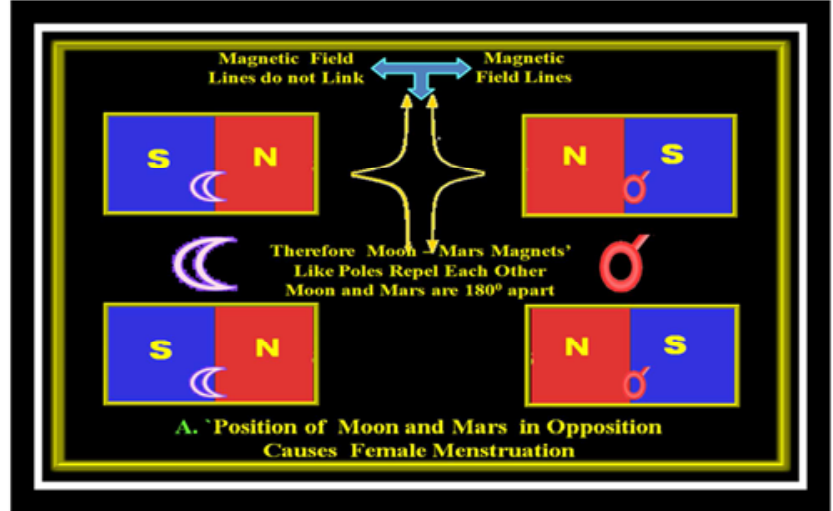

Figure 2. Transit Moon and Natal Mars are $180^{\circ}$ apart with their like poles oriented towards each other resulting in repulsion.

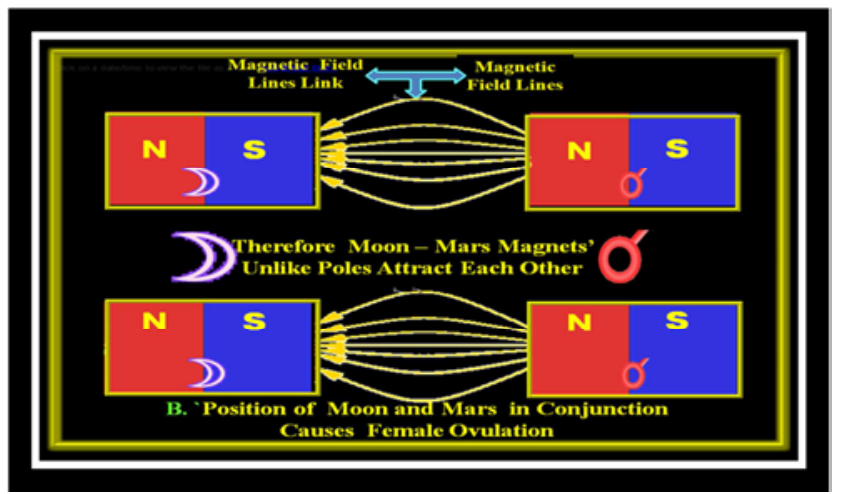

Figure 3. Transit Moon and Natal Mars in conjunction with their unlike poles oriented towards each other resulting in attraction.

Menstrual blood contains invaluable stem cells. Menstrual cycle in women is possibly brought about by Moon and Mars. These are the very source of stem cells for curing Alzheimer disease and bone marrow affliction, the two diseases pertaining to the brain and bone marrow damage signified by Moon and Mars respectively according to Vedic Astrology is quite amazing.

\section{Fertilisation, Formation of Zygote, Embryo, Foetus and Dna}

A zygote, embryo and fetus are all similar. The product of fusion of the nuclei of the sperm and egg is called zygote which possesses half the DNA of each of its two parents. it is unicellular. In humans, an embryo is generally considered to be between the first and the eighth week of development after fertilization and from then it is instead called a fetus. Some definitions consider embryological life to start at the third week of development to the eighth, when most organ systems are developing. The development of the embryo is called embryogenesis. The stage of the embryo which resembles a human being is called a fetus [6]. 


\section{Vedic Astrology and Stem Cells of Menstrual Blood}

In Vedic Astrology, Moon is the Mātrukāraka or the significator of the Mother and the Sun is the Pitrukārakaor the significator of the father in every horoscope irrespective of the Ascendant Sign. They are the lords of the two consecutive signs, Cancer and Leo respectively, in the Zodiac [7].

Humans have 23 pairs of chromosomes including one sex chromosome. Males will have XY sex chromosome whereas females will have XX sex chromosome. The parents together have 46 pairs of chromosomes. From each pair, the child draws one gene from the father and one from mother. In all, the child will have 23 pairs chromosomes in every cell including one pair called the Sex chromosome which decides the gender of the child. A zygote possesses half the DNA of each of its two parents [7] (Figure 4).

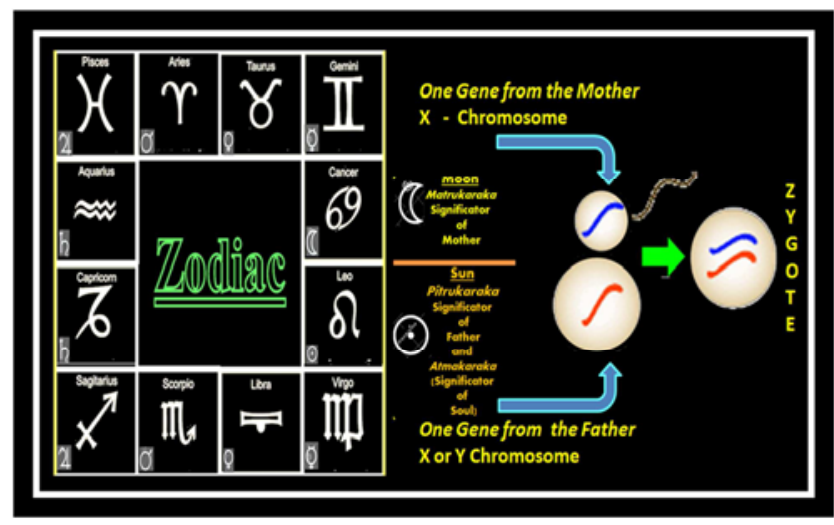

Figure 4. Relationship of in Zygote and Vedic Zodiac.

Further, interesting factor is the 7 Planets, 12 Signs of the Zodiac and the 27 Nakshatras, signifying the Gender of the Native, sum upto 46 (23 pairs) of Human Chromosmes.

Seymour's finding that fetus responds to daily lunar magnetic variation and not to its position in sky per se suggests that DNA of fetus might be varying during gestation period and finally fixed at the time of child's birth. This seems to be the correct view insofar as the DNA is unalterable and coexists with unalterable destiny of the native defined by the planetary configuration and particularly the position of the Moon at the time of birth in the chart of the native giving rise to the major planetary periods the native is to pass through during his period of longevity [7].

\section{Dna Applications and Gaquelin'Sky123.Org Planetary Heredity Principle}

As there are no two persons to a horoscope, or finger prints, or finger print of DNA, each human being is unique in his/her own way. The study of DNA in relation to cosmos, cosmic magnetism and in turn to Astrology may open new doors in understanding the planets' role in bringing about an event in life [8]. The conventional fingerprint occurs only on the fingertips and can be altered by surgery whereas a DNA fingerprint is the same for every cell, tissue, and organ of a person. It cannot be altered by any known treatment just as fate that cannot be altered or thwarted. It is useful in fighting fraud. It is found useful in uncovering the inherited diseases. In addition to forensics, DNA has been used to unite families. The most important use of the DNA fingerprinting is the personal identification. DNA finger printing is used in accurately recognizing the DNA of a person. Personal identification has been a boon in many fields, namely crime investigation and forensics. DNA fingerprinting is used in paternity testing while in some cases it may also be used to determine the identity of the mother. Consequently, DNA fingerprinting is rapidly becoming the primary method for identifying and distinguishing among individual human beings [9].

\section{Position of the Moon and the Planetary Periods in Vedic Astrology}

Exact position of Moon in the chart is of utmost importance in vedic astrological progressive horoscopy. It means the exact longitude of the Moon, measured from the vernal equinoctial point (VEP), at the correct moment of birth. What constitutes the correct moment of birth is a subject matter for discussion in a separate paper at a later date. The first nine days from birth during which the Moon passes through $120^{\circ}$ in the zodiac unfold themselves into nine planetary periods, the total duration of which is 120 years. Ancient Hindus considered the maximum of span of life of humans in this eon (Kaliyuga). Of course, Vedic Astrology is not blind to abnormal longevity i.e., span of life beyond 120 years. In $120^{0}$ there are nine spaces of $13^{13^{0}}$ each. Each $13^{1 / 3^{0}}$ of motion of the Moon from the (VEP) represents a daśa. The extents of the nine daśas are not uniform. The daśas which an individual has to pass through his life depends on the longevity of the native determined from the natal chart. The planetary configuration in the chart and the daśasoperating during the life of the native enables astrological divination and timing of events, in other words, the native's unalterable destiny [10] (Table 1).

Table 1. Planetary Daśas of Vedic Astrology.

\begin{tabular}{|c|c|c|c|c|c|c|c|c|c|}
\hline S1.No & 1 & 2 & 3 & 4 & 5 & 6 & 7 & 8 & 9 \\
\hline Planets & Mer & $\begin{array}{l}\text { SL } \\
\text { Node }\end{array}$ & $\mathrm{Ve}$ & Sun & Moon & Mars & $\begin{array}{l}\text { NL } \\
\text { Node }\end{array}$ & Jup & Sat \\
\hline Years & 17 & 7 & 20 & 6 & 10 & 7 & 18 & 16 & 19 \\
\hline
\end{tabular}

\section{Results}

i). Gauquelin's planetary heredity links involving the fourpronged pattern, for Venus, Mars, Jupiter, Saturn, and the Moon, is very similar to the shape of the average lunar daily magnetic variation for one month suggests that the combined complex interactions of planetary forces might be acting 
upon the Moon because of which Moon plays such a great role in the life of a native from zygote stage to the point of point of termination of mundane existence.

ii). Pairs of planetary alignments dominate the solar cycle during specific periods. This means that certain conjunctions or oppositions of planets per se possess greater intensity than others. The human neural network has a threshold above which the magnetic fluctuations of given planets must be in order for it to respond to these signals. The two planets Mars and Moon when in opposition cause female menstruation and ovulation when they are in conjunction according to Vedic Astrology.Thus, the position of the transit Moon is important in the formation of the foetus. Once the foetus is formed, the foetus doesn't really respond to the position of the Moon in the sky per se, but to the lunar daily magnetic variation, according to Seymour is a plausible fact.

iii). Planetary magnetic signals perceived by the neural network of the foetus inside the mother's womb heralds the child's birth

iv). Gaquelin's planetary heredity principle of planetary influences of Venus, Mars, Jupiter, Saturn, and the Moon cause striking planetary similarities in the birth charts of parents and their children which are in corroboration with Vedic Astrology can be supplementary evidence to DNA finger printing test in cases of determining paternity/maternity of the child.

\section{Discussion}

i). In Vedic Astrology, the Sun, Lord of Leo, substitutes the earth. Moon, the earth's satellite, is the Lord of Cancer. These two planets as Lords of Leo and Cancer, two consecutive signs in the Zodiac, are treated as constituting one single unit, couple. Further, sun and the moon are the natural significators of father (pitrukāraka) and mother (mātrukāraka) and they have also 23 pairs chromosomes each respectively including one sex chromosome $\mathrm{X}-\mathrm{Y}$ in respect of Father and $\mathrm{X}-\mathrm{X}$ in respect of Mother. Moon takes 29.5 days for one revolution around the Earth and natal Mars being constant remains in the same sign only. The two planets coming in opposition to one another occurs once every month and lasts for about 3 days each time causing menstrual cycle. This phenomenon of these two planets occurring every month causing menstrual cycle in women and the effective duration of menstruation lasting for about 3 days is quite amazing in terms of duration and frequency of menstrual cycle.

The revolution period of 1 month of transit Moon (360 degrees) coincides with the frequency of menstrual cycle and the time of being in opposition (180 degrees) to Mars for 3 days in a sign (30 degrees) coincides with the duration of menstruation [16]. Female menstrual cycles begin more often during a New Moon. The study found a synchronous relationship between the menstrual cycles and lunar rhythm. Among 826 females with a normal menstrual cycle, aged between 16 and 25 years, more than 28 percent of all menstruations occurred around the New Moon. The proportion of menstruations at other times during the lunar month ranged between 8.5 and 12.6 percent.

ii). Pregnant women spontaneously deliver more often during a Full Moon. The study that examined all full-term spontaneous deliveries (without mechanical or drug intervention) at the Civil Hospital, Fano during a two-year period found a significant relationship in women who had one or more previous pregnancies and their deliveries clustered around the Full Moon. Next comes the right time. It is an established fact that ovulation takes place 14 days after the menstrual period starts. But not everyone has a consistent 28 days' period. Studies have shown that the probability of getting pregnant is highest during the week before and on the day of ovulation.

iii). Ovulation in women happens about two weeks before the next expected menstrual period. Ovulatory disorders are one of the most common reasons why women are unable to conceive. Medically failed ovulation cases may be thought of, for a suitable magnetic therapy in the light of above hypothesis after regularising the menstrual period as suggested herein.

iv) The revolution periods of Mars, Moon and Jupiter orchestrates the frequency of female menstruation, ovulation and fertilisation besides gestation period.

v). The magnetic fields carry the prāna (life), and everyone interacts with these fields everywhere one turns. Magnetism is not just a hidden force that everyone interacts with. Love is an outstanding example of one kind of prāna. This is a natural physical magnetism that occurs between one and all physical things including people and animals, and is felt as either attraction or repulsion.

vi).Vedic Astrology is called 'Jyotish' which means light in Sanskrit. Everyone is curious to know his or her future. Jyotish provides light to all groping in the dark to know what is in store for him or for her. Vedic Astrology called Vedānga, one of the six limbs of the four ageless Vedas, of the ancient world, might have been developed as an orderly methodology of astrological divination and timing of events, with inherent understanding and knowledge of all disciplines of Science and Arts, perhaps, even more.Interestingly enough, life building blocks of DNA [11, 12] and hidden magnetic messages are found in meteorites brought to the Earth from space [13] suggest origin of life.

vii). Gaquelin's planetary heredity principle of striking planetary similarities in the birth charts of parents and their children can be utilised as supplementary evidence to DNA finger printing test in cases of determining paternity/maternity of the child.

viii). Omnipresent throughout the universe, magnetism is known to affect the biological cycles of numerous creatures here on Earth, including humans. 'Man, is a Microcosm of the Macrocosm, the Universe' [14]. Lunar Magnetism appear to greatly influence the various stages of a native such as female menstrual cycle, ovulation, fertilisation, formation of zygote, development into embryo, foetus, child birth and all stages of life of the native to the point of termination of mundane existence. 
ix). From the foregone results and discussion of the importance of Moon for life to exist, the exploration for more potentially inhabitable planets and search for intelligent life on any other planet within our Solar System or elsewhere in the Universe, extrapolation of our Earth alone without the inclusion of its satellite, the Moon, does not serve the purpose.

\section{Scope for Future Research}

In so far the hypothesis of menstruation, ovulation and fertilisation is based on interactions of magnetism, a suitable magnetic therapy may be evolved for medically given up cases of infertility.

\section{Acknowledgement}

I thank my son, Prof. Y. V. RamanaRao, M. Tech., Ph. D., for his critical examination of the manuscript and offer of constructive suggestions in the final preparation of the subject matter as a research paper.

\section{References}

[1] Michel Gauquelin, Planetary Heredity, San Diego: ACS Publications, 1988. «Text.

[2] Percy Seymour, Cosmic Magnetism, Bristol, U.K.: Adam Hilger, 1986. «Text.

[3] Rao, Y. V. S, Moon-Mars Magnetism and Menstrual Cycle in Women, Journal of Advances in Philosophy Vol. 1, No. 1, 2015.
[4] Sastry, P. S, VarāhaMihira'sBrihatJataka, Ranjan Publications, New Delhi, 1995.

[5] KalyanaVarma, Saravali 1977, Publn: MotilalBanarsidas.

[6] En.wikipedia.org/wiki/Embryo.

[7] Rao, Y. V. S, Hindu Gotra System and Modern Genetics, Manuscript, http://cirworld.com/journals/index.php/japy/author/submission /3515 Journal of Advances in Philosophy online Journal Dec 2014.

[8] Natal Charts vis $-\mathrm{a}-$ vis DNA entries, Journal Advances in Philosophy, Vol.1. No.1, 2014.

[9] genetics.thetech.org/ask/ask20.

[10] Rao, Y. H. and Rao Y. V. S, Astrology on the Moving ZodiacThe One System for the East and the West, 2004, ISBN 817525-939-6; 9788175259393.

[11] Callahan, (Aug 9, 2011), DNA Blocks found in Meteorites, Proceedings of the National Academy of Sciences of the United States of America.

[12] A Relook at the definition of Meteorites, Journal of Astrobiology, 2015, Sciknowja_1418570523.

[13] http://www.gizbot.com/new/hidden magnetic-messages foundmeteorites-022156 January 22, 2015.

[14] Rao, Y. V. S, Man is a Microcosm of the Macrocosm, the Universe, Journal of Advances in Philosophy Vol. 1, No. 1, 2015. 